\title{
Correction to: Low-dose CT lung images denoising based on multiscale parallel convolution neural network
}

\author{
Xiaoben Jiang ${ }^{1} \cdot{\text { Yan } \operatorname{Jin}^{1}}^{1} \cdot$ Yu Yao $^{1}$
}

Published online : 21 December 2020

(c) Springer-Verlag GmbH Germany, part of Springer Nature 2020

\section{Correction to:}

\section{The Visual Computer} https://doi.org/10.1007/s00371-020-01996-1

The publication of this article unfortunately contained mistakes. The photos of Xiaoben Jiang and Yu Yao were exchanged. The corrected assignment is given below.

The original article has been corrected.

Publisher's Note Springer Nature remains neutral with regard to jurisdictional claims in published maps and institutional affiliations.

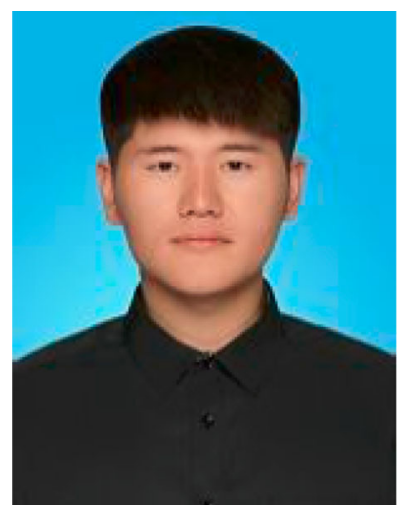

Xiaoben Jiang is studying as a postgraduate at Zhejiang University of Technology. His current research interests include digital image processing and computer vision.

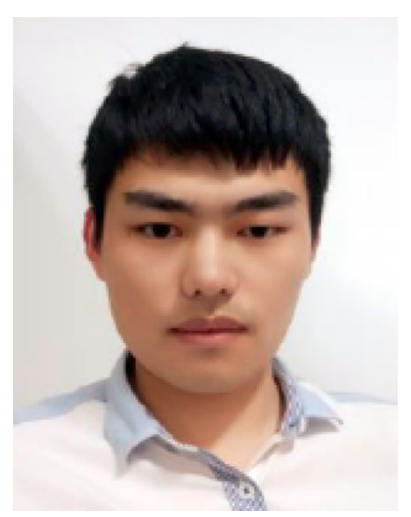

Yu Yao is studying as a postgraduate at Zhejiang University of Technology. His current research interests include digital image processing and computer vision.

The original article can be found online at https://doi.org/10.1007/s00 371-020-01996-1.

Yan Jin jy@zjut.edu.cn

1 College of Information Engineering, Zhejiang University of Technology, Hangzhou 310023, Zhejiang Province, China 